DE PARTNERKEUZE IN MODERN AFRIKA

Hugo DRIES

Laboratorium voor Experimentele, Differentiële en Genetische Psychologie (R.U.G.)

H. Dunantlaan 2 B-9000 Gent

Specialisatie : Psychologische antropologie, interculturele psychologie

"Een psycho-antropologisch onderzoek van de modernisatieproblematiek in Afrika : reacties en attitudes van moderne en traditionele Afrikanen t.o.v. het probleem der partnerkeuze"

\title{
SUMMARY
}

\section{Partnerchoice in modern Africa}

Partner choice in Africa was investigated in a modernization study. The research sample consisted of 275 adult males from the Zairean province of Shaba (university students, clerks, workmen and illiterate rurals). The sample was split up into two subgroups : the "moderns" and the "traditionals".

our main research instrument was a series of 14 pictures, inspired on the Thematic Apperception Technique.

Traditionally, it was the father, or the family, who arranged marriage for the son. Modern young Africans more and more want to choose their partner on their own. This modern attitude leads to a number of conflict situations, because, on the one hand. Africans want to realise their partner choice by themselves, but on the other hand, they do not like to endanger their relationships with the family.

KEYWORDS : Psychological modernization, partner choice, Zaire 
Tot voor kort meende men dat enkel het Westers familiemodel aangepast was aan het leven in een geindustrialiseerde en verstedelijkte gemeenschap en dat acculturatie en modernisatie vrijwel noodgedwongen zouden leiden tot een gezinsstructuur van het Westers type. Wat in Afrika (en in andere niet-Westerse gebieden) plaatsgreep was echter veel complexer, en zeker niet eenzijdig terug te brengen tot een zuivere vorm van imitatieve of passieve acculturatie.

In stedelijke Afrikaanse gemeenschappen kent de polygamie in haar orthodox-traditionele vorm zonder twijfel grote moeilijkheden, al was het maar om economische redenen. Polygamie, die in agrarische gemeenschappen inderdaad economisch verantwoord is omdat een belangrijk gedeelte van het produktieve werk er door de vrouw verricht wordt, wordt vrijwel onhoudbaar in een stedelijk milieu waar het produktieproces meer mannelijk georiënteerd is. Maar dit betekent niet dat deze polygamie zonder meer vervangen werd door de Westerse monogamie. De Afrikaanse stedeling mist dikwijls de middelen om de bruidsprijs te betalen of vindt in de stad, gekenmerkt door een duidelijk mannenoverschot, geen geschikte vrouw, en zoekt dan zijn toevlucht in prostitutie of in min of meer stabiele cohabitatie. De meer begoeden zijn enerzijds officieel meer monogaam. maar substitueren de polygame traditie door concubines te onderhouden, die dan eventueel later in een authentieke of syncretische polygame structuur worden opgenomen.

Met de verstedelijking geraken de traditioneel zo belangrijke familiebanden en -verplichtingen ook enigzins op de achtergrond. De uitgebreide familie blijft echter nog steeds de norm en, alhoewel de grote traditionele familiegroepen in de stad meestal niet meer samen (kunnen) wonen, overtreft het aantal samenwonende personen gewoonlijk dit der nucleaire familie. Ook de familiale solidariteit londer de vorm van gasturijheid, mutuele bijstand, financiële hulp, e.d.) blijft in de mate van het mogelijke gehandhaafd, alhoewel deze traditionele waarde voor vele stedelijke Afrikanen enorme problemen schept en niet zelden degenereert naar een werkelijk parasitisme. 
Ondanks dikwijls heftige tegenstand en kritiek handhaaft de bruidsprijs zich als een centraal gegeven in het Afrikaans familiaal systeem, en eerder dan te verdwijnen, ondergaat deze bruidsprijs ook functionele- en vormveranderingen, vervangt geld progressief de traditionele betaalmiddelen, en wordt het vereffenen van de bruidsprijs meer en meer een persoonlijke aangelegenheid, in die zin dat hij door de toekomstige bruidegom zelf betaald wordt en minder, zoals het traditioneel het geval was, door de ganse uitgebreide familie of clan.

Dit breed geschetst overzichtbeeld van de Afrikaanse familieproblematiek kan als algemeen referentiekader doorgaan voor een meer gedetailleerde bespreking van een belangrijk aspect ervan, nl. de partnerkeuze.

\section{De partnerkeuze}

Alhoewel de partnerkeuze op zichzelf geen fundamenteel aspect is van de huwelijkssituatie, krijgt ze in Afrikaanse context toch extra belangstelling, omdat het zelf kiezen van de huwelijkspartner door velen gezien wordt als een concrete manifestatie van modernisatie en emancipatie. Het relatieve belang van deze persoonlijke partnerkeuze komt reeds sprekend naar voren in een oudere publikatie van JAHODA (1959), waarin hij een analyse maakt van de "Courier du coeur" in een plaatselijk (Ghanees) dagblad. Problemen in verband met door ouders of door familie opgdrongen partnerkeuze, en oppositie van de familie tegen persoonlijke partnerkeuze nemen daarin een belangrijke plaats in $129 \%$ der brieven van ongehuwde mannen) (2).

Deze opgedrongen partnerkeuze wordt namelijk als symptomatisch gezien en aangevoeld voor het traditionele huwelijk, dat een pact was tussen twee groepen. In een dergelijke context "ce sont les parents qui choisissent la fiancee" (MWEPU-KYABUTHA, 1967, p. 66) en, zoals gezegd, meestal ook instaan voor de bruidsprijs (DEKKERS, 1968 ; MONONI, 1968). Het traditoneel huwelijk is een sociaal 

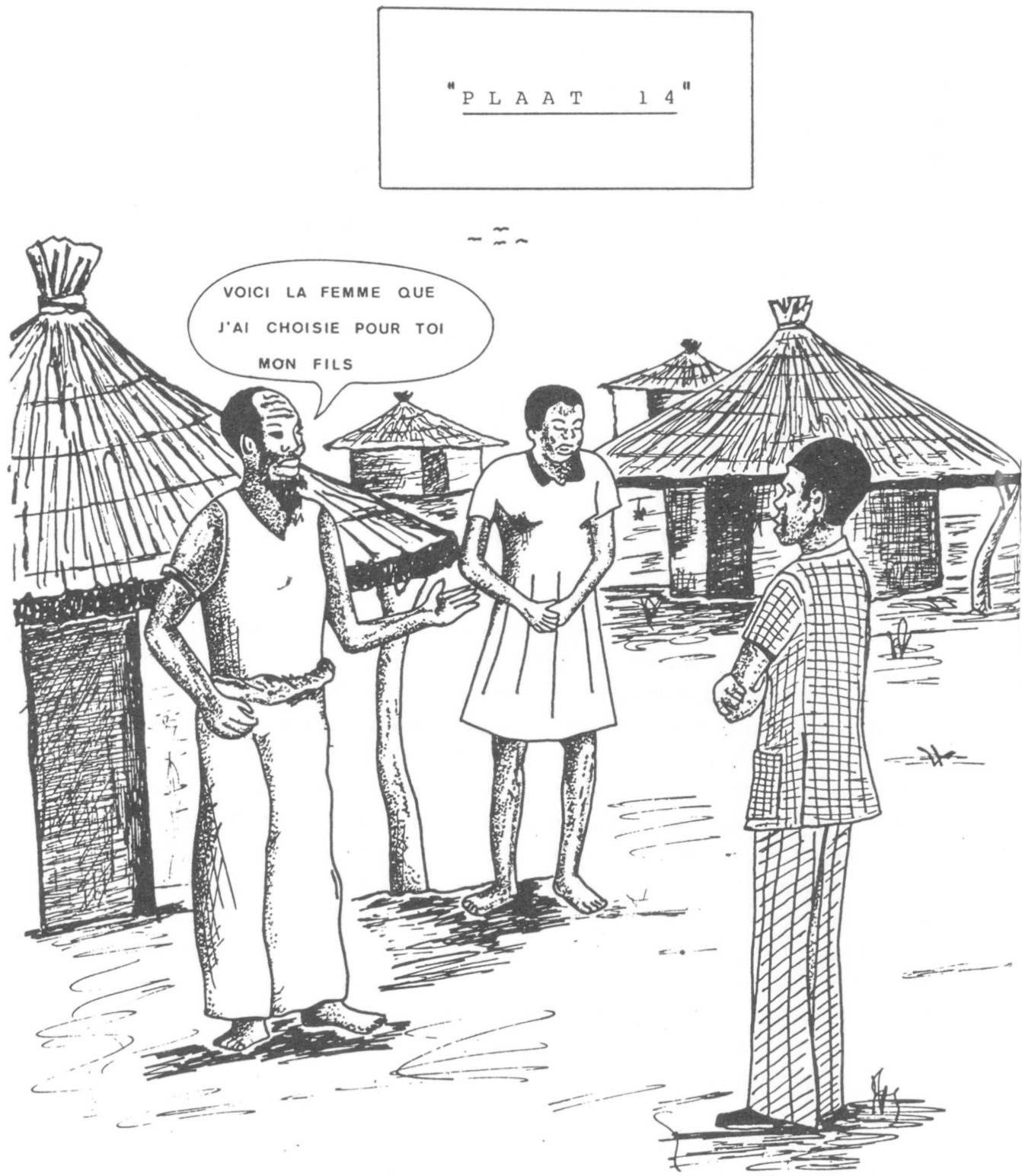
3. Thematisch modernisatieonderzoek in Zaire (3)

a. Proefgroep en methode

Het onderzoek waar hier naar verwezen wordt, greep plaats in de Shaba-provincie en heeft betrekking op 275 volwassen mannelijke proefpersonen, waaronder 70 universiteitstudenten, 70 bedienden en 70 arbeiders uit de provinciale hoofdstad Lubumbashi, en 65 dorpelingen uit sambwa leen middelgroot dorp, $35 \mathrm{~km}$ ten zuiden van Lubumbashi).

De gemiddelde leeftijd der subjecten bedroeg 30 jaar. De dorpelingen zijn overwegend ongeschoold $(57 \%)$, de studieervaring der arbeiders beperkte zich vooral tot het lager onderwijs, terwijl de bedienden meestal een aantal jaren secundair onderwijs gevolgd hadden. De universitairen zijn vooral licentiaatsstudenten $(61 \%)$.

Andere variabelen die bij de beschrijuing van de proefgroep in rekening gebracht werden, zijn "milieu" (ruraal-stedelijk) en "familiale toestand". De ethnische achtergrond en de ideologie der subjecten zijn gekend, maar werden wegen: hun irrelevant karakter niet in de verwerking betrokken.

In dit onderzoek werd gebruik gemaakt van een door ons ontworpen veertiendelige reeks aangepaste thematische platen van het TAT-type. (Thematic Apperception Test). De thema's welke in deze platen aan bod komen, zijn achtereenvolgens :

1. schoolgaand meisje in een ruraal milieu

2. moderne versus traditionele economische activiteit

3. stedeling in dorp

4. biogeneeskunde versus ethnogeneeskunde

5. familiale solidariteit

6. polygame familiestructuur

7. clorpeling in de stad

8. tovenarij en magie

9. consumptiepatroon

10. sociaal en fysisch isolement 
11. dood

12. generatieconflict

13. autoriteit

14. opgelegde partnerkeuze

De in de tekst besproken problematiek heeft betrekking op de hierbij afgebeelde plaat 14 . Deze plaat is een evocatie van de traditionele situatie, waarbij een oudere man een meisje aanwijst als huwelijkspartner voor zijn zoon. De scène speelt zich af in een ruraal milieu. Om de interpretatie van deze situatie te vergemakkelijken werd bij het gebaar van de vader een begeleidende tekst voorzien ("Voici la femme que j'ai choisie pour toi, mon fils"), die ofwel door de proefpersoon zelf of door de proefleider gelezen en eventueel vertaald werd.

\section{b. Verwerking en interpretaties der gegevens}

De door de proefpersonen geproduceerde verhalen (volgens de TAT-techniek) werden hoofzakelijk geanalyseerd volgens een procedure die gebruikelijk is bij het verwerken van open vragenlijsten, en meer in het bijzonder volgens een categorisatie der reacties.

Om het in rekening brengen van de onafhankelijke variabelen (beroep, milieu, studieniveau en leeftijd) een zo realistisch mogelijk karakter te bezorgen, werd bij de verwerking van de gegevens uitgegaan van levensechte constellaties. Concreet werden binnen de groep van 275 proefpersonen. twee subgroepen onderscheiden waarin deze variabelen in samenhangende combinaties voorkomen. Deze beide subgroepen, die we conventioneel de "modernen" en de "traditionelen" noemen, bestaan elk uit 100 subjecten. De modernen zijn daarbij overwegend studenten en bedienden. hebben meer gestudeerd, hebben een belangrijke stedelijke ervaring en zijn jonger dan de traditionelen, die vooral bestaan uit landbouwers en arbeiders.

De basisprocedure van de hiernavolgende verwerking zal bestaan uit een comparatieve benadering van deze beide subgroepen. 
Bij de bespreking van de reacties der subjecten zullen we twee dimensies onderscheiden : de motieven van de vader, en de reacties van de zoon.

1) Motieven van de vader

Dit criterium voor analyse gaf aanleiding tot volgende categorieën :

Code

Motivatie van de vader

0

geen motivatie aangegeven

1

vader stelt partner voor omdat de zoon de huwbare leeftijd bereikt of dreigt deze te overschrijden

vader stelt huwelijkspartner voor om het mislopen van de zoon te vermijden of tegen te gaan

huwelijkskandidate wordt voorgesteld met het doel het nageslacht te verzekeren

vader volgt de traditie, die eist dat hij een nuwelijkspartner voor zijn zoon uitkiest

vader handelt uit goedheid, wil geschenk aan zoon geven

vader baseert zijn keuze op een aantal criteria : hij kent het meisje, het is een meisje uit het dorp, is werklustig, zal een goede vrouw zijn

De reacties van beide subgroepen zijn weergegeven in Tabel 1. Zoals blijkt is het verschil tussen modernen en traditionelen niet significant. Toch wordt de significantiedrempel nauwelijks overschreden $(p=.064)$, zodat eventueel wel van een verchil in accenten kan gesproken worden (4). 
dezelfde motieven aan de vader toekennen, kan er toch op gewezen worden dat bij de traditionelen een overwicht bestaat aan meer paternalistisch georienteerde achtergronden van de vaderlijke beslissing, en een verwijzing inhouden naar een mogelijke vorm van onmondigheid van de zoon, terwijl de motieven van de modernen meer een vorm van naieve goodwill van de vader suggereren : hij meent het zeer goed, maar zijn houding beantwoordt niet (meer) aan de realiteit. Dit betekent dat bij een weigering van de zoon, de reacties van de vader overwegend in de sfeer van verwondering en ontgoocheling zullen liggen.

2) Reacties van de zoon

Deze centrale variabele van plaat 14 werd als volgt gecatalogeerd :

Code Reactie van de zoon

o geen reactie, onbruikbaar antwoord

1 voorgestelde partner wordt enthousiast aanvaard. of aanvaarding zondermeer

2 aanvaarding onder druk van de autoriteit van de vader, onder druk van de traditie, enz.

3 formele aanvaarding, gevolgd door latere weigering

4 uitstel van beslissing : zoon vindt zichzelf te jong. moet studies afmaken, vraagt bedenktijd

5 weigering na overtuiging van vader, geen conflict

6 weigering zonder meer, conflict

7 een der bovenstaande reacties, met moraliserende bedenkingen ten gunste van de traditie

8 een der bovenstaande reacties, met moraliserende bedenkingen ten nadele van de traditie 
Zoals blijkt uit Tabel 2, zijn de reacties van beide subgroepen zeer significant verschillend en kenmerkt dit verschil zich in een uitgesproken overwicht aan negatieve reacties van de zoon bij de modernen. Het groeperen van respectievelijk positieve en negatieve reacties brengt dit nog duidelijker aan het licht. Bij de traditionelen zijn er namelijk 53 (codes 1,2 en 7) waarbij de zoon op één of andere manier instemt met de door de vader voorgestelde partner, bij de modernen zijn dit er slechts 9.

Tabel 2 : Plaat 14 : reacties van de zoon

AANTAL VERHALEN PER SUBGROEP

\begin{tabular}{|c|c|c|c|}
\hline code & reacties (verkorte vorm) & Modernen & Tradj \\
\hline 0 & geen & 1 & 6 \\
\hline 1 & enthousiaste aanvaarding & 2 & 30 \\
\hline 2 & a anvaarding onder druk & 7 & 18 \\
\hline 3 & formele aanvaarding & 24 & 7 \\
\hline 4 & uitstel van beslissing & 4 & 5 \\
\hline 5 & a fwijzing zonder conflict & 48 & 14 \\
\hline 6 & afwijzing na conflict & 14 & 11 \\
\hline 7 & moraliserend pro traditie & - & 5 \\
\hline 8 & moraliserend contra traditie & e & 4 \\
\hline TOTAAL & & 100 & 100 \\
\hline
\end{tabular}


Het verwerpen van vaders keuze (codes 3, 5, 6 en 8) komt bij 86 modernen voor en slechts bij 36 traditionelen. Het kiezen van de huwelijkspartner door ouders of familie is dus een traditionele cultuurtrek die duidelijk door de modernisatie aangetast is.

De concrete omstandigheden waarin dit afwijzen of aanvaarden van vaders keuze gesitueerd wordt en de argumenten waarop deze houding gebaseerd is, kunnen we terugvinden in een reeks verhalen of fragmenten van verhalen. In een aantal gevallen geeft deze plaat aanleiding tot totaal probleemloze verhalen. Sommige traditionelen moeten zich blijkbaar afgevraagd hebben waarom deze plaat werd aangeboden, omdat ze een in hun ogen totaal evidente toestand uitbeelden. Het al dan niet instemmen door de zoon met de keuze van de vader komt gewoonweg niet ter sprake, of wordt alleszins niet in vraag gesteld.

Volgend verhaal is een voorbeeld van een dergelijke reactie :

"Un père dit à son fils : 'Mon fils, voici ta femme'. Le fils répondit : 'papa, je suis très content d'avoir une femme. Je vais construire une maison et nous serons heureux tous les deux et nous allons t'aider, car tu es vieux'. Le fils se maria, vécut heureux avec sa femme et aida son père". (nr. 116. arbeider).

Het aanvaarden van de voorgestelde partner wordt in de meeste gevallen echter op de een of andere manier gemotiveerd. Dikwijls zijn deze motivaties variaties op het thema "Vader weet het best", zoals in volgend fragment :

"Le papa a raison. Il a vu que son fils devient adulte et qu'il a l'âge de se marier. Il prendra la femme que son père a choisie pour lui, car le papa sait le mieux quelle femme convient à son fils ...". (nr. 115, arbeider).

Soms biedt de traditionele procedure verrassend positieve perspectieven :

"... Le fils accepte la femme que son père lui a choisie. Il veut vivre tranquillement avec sa cousine paternelle. Le papa a 
prèféré donner à son fils une fille de sa famille, pour qu'il ne soit menace par aucun danger. Tous deux sont de la famille, par conséquent aucune belle famille ne peut déranger le fils". (nr. 248, landbouwer).

Buiten deze probleemloze, al dan niet gemotiveerde reacties, treffen we verhalen aan waarin het aanvaarden van de voorgestelde partner minder spontaan gebeurt, maar het gevolg is van een druk die op het individu wordt uitgeoefend. In bepaalde gevallen neemt deze pressie huiveringwekkende vormen aan, zoals in volgend fragment :

"... Quand le père présenta la femme à son fils, le fils refusa et dit qu'il doit d'abord terminer ses études. Le père se fácha et dit : 'Si tu ne prends pas cette femme je ne te donnerai plus mon argent pour aller à l'ecole et je te chasserai de chez moi. Je veux que tu te maries et que tu aies des enfants avant ma mort'. Devant les menaces de son père. le fils accepta la femme et abandonna ses études". (nr. 118. arbeider)

De machtsverhouding tussen vader en zoon is soms zo, dat er geen alternatief is voor de vaderlijke autoriteit :

"... Le fils est trop pris par l'autorité paternelle. Il est obligè de se résigner et de prendre en mariage cette fille qu'il n'aime pas". (nr. 274, landbouwer).

In deze context wordt de bruidsprijs meer dan eens als drukkingsmiddel gebruikt. Zoals vermeld was de bruidsprijs traditioneel een collectieve aangelegenheid, waarvoor de groep van de toekomstige bruidegom instond. In de praktijk speelde de vader (of een equivalente figuur) daarbij een belangrijke rol. Een niet instemmen met de door de vader voorgestelde partner kan dan met zich meebrengen dat de vader dreigt niet meer tussen te komen in het betalen van de bruidsprijs :

"Ce papa s'est arrangé avec la famille de son ami pour le mariage de son fils ... Le fils répond non et tient à continuer ses études ... Le fils dit à son papa qu'à la fin de ses études il 
présentera seul sa fiancèe à son pere. Mais le père répond que dans ce cas, il ne mariera plus son fils, et qu'il devra $s^{\prime}$ occuper tout seul de la question de la dot. Devant ces menaces, le fils accepta sans joie la fille". (nr. 196, landbouwer).

Alhoewel de partnerkeuze zeker geen prioritair domein is voor magische praktijken en overtuigingen, komen deze aspecten in een aantal protocollen toch min of meer expliciet aan bod. Door negatief te reageren op het voorstel van de vader verzaakt het individu tegelijkertijd aan een aantal beveiligingsmechanismen en stelt zich meteen bloot aan gevaren en magische represailles.

"... Mais le garçon n'est pas d'accord ... il refuse, il sera mal vu par son père et il peut avoir des malheurs ..." (nr. 58, arbeider) en

"... quand on n'écoute pas la parole de son père, on ne sait pas ce qui va arriver pendant son union ...". (nr. 166, arbeider).

Om deze gamma van beweegredenen af te sluiten, vermelden we tenslotte een typische situatie die in de acculturatieliteratuur regelmatig beklemtoond wordt en die beschreven wordt als anti-acculturatie, of een zich expliciet en bewust regressief afkeren van moderne of vreemde modellen. Plaat 14 heeft nagenoeg geen dergelijke reacties uitgelokt. Dit staaft onze overtuiging dat deze antiacculturatie in het effectief gedrag een marginaal verschijnsel blijft en zich grotendeels beperkt tot een zich niet engagerende, al dan niet demagogisch geinspireerde pose. Eventueel zou volgend verhaal kunnen verwijzen naar een vorm van anti-acculturatie :

"Ce garçon arrive chez lui au village pour parler à son père de sa fiancée qu'il a déjà aimée. A peine a-t-il ouvert sa bouche pour le dire que son père lui présente une fille qui $n$ 'est pas de son goût. ... Le jeune homme le surprendra en avouant à son père qu'il abandonne celle de la ville pour prendre celle que lui ont choisi les ancétres par l'intermédiaire de son père. Car, estime-t-il, c'est elle et elle seule qui pourra fournir un héritier au clan". (nr. 92, student). 
De tot hiertoe vermelde verhalen zijn voorbeelden van wat we klasseerden bij de groep der positieve reacties, d.w.z., verhalen waarin de zoon op een of andere manier daadwerkelijk huwt met het door de vader voorgestelde meisje. Zoals blijkt is het realisatiepatroon van deze positieve afloop echter erg uiteenlopend en gaat van een enthousiast, kritiekloos en spontaan aanvaarden en beamen van het ouderlijk voorstel, tot een situatie waarin de huwelijksbelofte slechts na dreigementen of op grond van morele en materiele pressie tot stand komt.

Wanneer we dus spreken over 9 positieve reacties bij de modernen en 53 bij de traditionelen, dienen deze frequenties gerelativeerd te worden in functie van de graad van positiviteit van deze reacties.

Met deze correctie blijven er van de modernen nog 2 zuiver positieve reacties over, en bij de traditionelen 30 . Concreet zou dit betekenen dat in een populatie die wij modern noemden, dit traditioneel huwelijksgebruik, althans als waarde, dus op het psychisch en mentaal vlak, praktisch volledig afgeschreven is.

De vraag blijft uiteraard in hoeverre deze mentale modernisatie zich tevens waar maakt in het reëel handelingspatroon.

De inhoudelijke differentiatie die we aantreffen bij de negatieve reacties zal uiteraard groter zijn dan bij deze der besproken positieve reacties.

Zoals het geval was in de positieve sfeer, treffen we ook hier verhalen aan die zich beperken tot een niet gemotiveerde in dit geval - botte weigering: de vader stelt een meisje voor, en de zoon weigert zonder meer :

"... Ses parents apprirent la nouvelle et lui cherchèrent une fille à marier dans le village. Le fils refusa la fille". (nr. 83. student).

Toch komt een dergelijke botte reactie uiterst zelden voor. In gans het pakket verhalen troffen we slechts 3 van deze situaties aan. Het is blijkbaar niet zo evident om zonder meer, of zonder geldige argumenten longeacht de objectieve geldigheidsgraad ervan) tegen de wil van de ouders in te gaan. 
Dit stemt overigens overeen met de hierboven vernoemde positieve motivaties van de vader. Over het algemeen is de relatie met de vader goed en streeft men naar een instandhouding van deze verhouding, wat niet betekent dat men de vader steeds en zonder meer zal volgen of gehoorzamen, en zeker niet in verband met de partnerkeuze. Daarom dienen er in de situatie argumenten gezocht en gevonden te worden die een weigering van de zoon kunnen rechtvaardigen. Meestal hangen deze samen met kenmerken van het meisje : men vindt ze oud, lelijk, incult, ze is dorpelinge, enz.

"... Un jeune homme, tel que celui que nous voyons ici, souhaiterait choisir lui-même. D'ailleurs sa mimique prouve suffisamment qu'il ne veut pas d'imposition, et surtout pas de cette fille manifestement inculte". ( $n r .16$, bediende).

"... Moi je pense que ce jeune homme s'opposera au choix de son père. $D$ 'abord parce que lui a fait des études, tandis que la jeune fille parait inculte, ensuite cette fille est plus âgée. semble-t-il que le garçon ...". (nr. 18, bediende).

"Un père aime beaucoup son fils ... il lui a cherche une femme. mais la femme est plus âgée que le garçon. Le fils dit alors à son père. 'La femme que vous me donnéz est vieille, je ne la veux pas, j'irai moi-même chercher une fille'. (nr. 120. arbeider).

Vermits de jonge man op plaat 14 steevast als een stedeling (student, bediende, zakenman) geidentificeerd wordt, komt als argument voor de weigering regelmatig het dorpse uitzicht en de dito mentaliteit van het meisje aan bod, al dan niet expliciet gecombineerd met de gedachte dat een dergelijk meisje zich niet zal kunnen aanpassen in de stad, dat men zich in de stad met een dergelijke partner belachelijk maakt, enz. :

"... Le père insiste, mais le garçon persiste dans son refus. Il a peur de venir se faire ridiculiser auprès des amis en ville, lorsqu'ils verront cette villageoise sans manières ..." (nr. 203. bediende). 
Andere redenen die worden aangehaald om een weigering te verantwoorden situeren zich bij de jongen of in zijn situatie : hij is te jong, moet nog verder studeren, heeft reeds een verloofde in de stad, enz. Deze argumenten komen op verchillende niveaus van realiteit voor : soms beantwoorden ze aan de werkelijkheid, en in andere gevallen worden ze als voorwendsel gebruikt.

"Ce jeune homme est un étudiant. Il est en vacances chez ses parents. C'est avec une grande surprise qu'il écoute ce que le père lui dit. Le père a cru faire un choix judicieux pour son fils. Le garçon se révolte et dit qu'il est trop jeune pour se marier. Mais la vraie cause de son refus n'est pas celle-là. II voudrait plutôt épouser une jeune fille instruite et pas une illettrée comme celle-ci. Le père est aussi surpris de voir que son fils refuse. De son temps un fils devrait plutôt s'incliner devant la décision du père". (nr. 34, bediende).

Zoals gezegd werden we getroffen door het respect en de liefde voor de vader die in de meeste verhalen tot uiting komen, zelfs wanneer het voorstel van de vader niet ingevolgd wordt. Sprekend komt dit tot uiting in volgende fragmenten :

"... Son père lui présente une fille à marier. Le garçon n'accepte pas la fille, parcequ'elle est trop âgée ... En tout cas, le garçon n'accepte pas, malgré le respect qu'il a pour son père". (nr. 89, student).

"... Son papa, en bon coutumier, a cru bon de lui choisir une jeune fille répondant aux exigences de la coutume... Il lui présente l'épouse idéale selon ses normes. Malgré le respect qu'il porte à son père, le garçon refuse cette jeune fille...". (nr. 25, bediende).

Bovendien valt het op dat in deze situatie, waar het uiteindelijk gaat over drie afgebeelde personages, slechts melding gemaakt wordt van motieven, houdingen, uitspraken en reacties van vader en zoon, maar dat het meisje systematisch op de achtergrond geplaatst wordt. In geen enkel van de 200 verhalen komt het meisje aan het woord, of 
wordt het woord tot haar gericht. Er wordt wel veel over het meisje gepraat, maar nooit tegen haar. Wanneer er naar de reacties van het meisje verwezen wordt, beperken deze verwijzingen zich grotendeels tot het evoceren van passieve houdingen : ze is blij, bedroefd, ze hoopt, vreest, enz., maar nooit komt zij actief tussen of tracht effectief in te grijpen op het verloop der gebeurtenissen.

"... La femme ne dit rien, elle souhaite que le jeune homme puisse l'accepter...". (nr. 42, bediende).

"... Ce refus rend la fille malheureuse ...". (nr. 209, bediende).

Alhoewel de term misschien storend overkomt, ontsnappen wij niet aan de indruk dat in deze situatie het betrokken meisje meer als object benaderd wordt dan als een eventuele partner. Deze opvatting kenmerkt de meeste verhalen en in bepaalde gevallen klinkt het werkelijk cynisch :

"... Il dit au papa qu'il va réfléchir. Il profitera de cette fille pendant les vacances pour tromper l'opinion. Mais une fois rentré aux études, il écrira à son père pour lui manifester son refus d'épouser une villageoise et de surcroit une illettree". (nr. 67, student).

Tot welke excessieve toestanden een dergelijke houding kan leiden, blijkt uit volgend fragment :

"... Son fils refusa et lui dit qu'il fallait plutôt mourir que l'épouser. Tout honteux, le pere rentra avec elle et fut contraint à la prendre pour la sienne". (nr. 126, arbeider).

Deze grondhouding ligt tevens aan de basis van een aantal typische oplossingen voor het probleem der partnerkeuze : ogenschijnlijk gaat de zoon in op de keuze van de vader en huwt met het meisje, maar doet dit slechts om de vader te sussen ; dit huwelijk wordt door de zoon namelijk expliciet als voorlopig voorgesteld, en zodra de gelegenheid zich voordoet (met name, zodra hij terug in de stad is) zal hij het meisje van zijn persoonlijke keuze huwen. Deze reactievorm, die we met BALANDIER (1971, p. 281) een "formalisme 
tactique" zouden kunnen noemen, treffen we o.a. aan in het volgend fragment :

"... Le garçon hésite, il sait ce qu'il veut : jamais il n'épousera cette fille. Mais il craint de trop décevoir son pere qui pourra être frustré de ce refus. Il accepte provisoirement. le moment se présentera pour s'en débarasser". (nr. 68, student).

Zoals dus uit vele verhalen blijkt, wordt het meisje niet in de discussie betrokken ; zij is geen gesprekspartner, haar houding, haar mening wordt op geen enkel ogenblik in rekening gebracht. De zoon wacht tot het meisje weggaat of weggestuurd wordt om ernstig met de vader de zaken te bespreken :

"... Il dit à son père qu'il préfère se marier à une fille de son choix. Mais cela il le dira quand la jeune fille sera partie ...". (nr. 21, bediende).

\section{Discussie en Besluit}

Het overzicht van reactiepatronen op de stimulus die de problematiek der partnerkeuze oproept, geeft reeds een aantal belangrijke aanwijzingen in verband met de modernisering van het Afrikaans huwelijk en familieleven. Alhoewel in de gespecialiseerde literatuur de evolutie van het Afrikaans huwelijk beschreven wordt als een progressief verdwijnen van de traditioneel uitgebreide familiestruktuur ten voordele van de Westerse biologische kernfamilie (GOUGH, 1977 HUNTER, 1967 GOODE, 1973) moeten degelijke algemene uitspraken bijzonder genuanceerd geinterpreteerd worden.

De tendens dat een aantal traditionele praktijken verloren gaat bestaat inderdaad wel : na de analyse van plaat 14 is het onder meer duidelijk dat de rol der ouders in de partnerkeuze door de modernisering is aangetast. De moderne Afrikanen ambiëren duidelijk een meer persoonlijke inbreng in de keuze van de huwelijkspartner. Om een aantal 
redenen blijkt het ideaal echter te bestaan in een overeenstemming tussen de keuze van de vader en deze van de zoon zelf. Zonder dat de besproken plaat expliciet daarop inspeelde blijkt deze evolutie eveneens repercussies te hebben op de bruidsprijs. Het persoonlijk instaan voor de keuze van de huwelijkspartner brengt geen verdwijnen met zich mee van de bruidsprijs, maar leidt tot een individualisering ervan, in die zin dat - vooral bij conflictsituaties tussen vader en zoon - de bruidsprijs meer en meer persoonlijk door de bruidegom moet vergaard worden.(5).

Maar, wanneer de man zelf een belangrijke rol speelt in de partnerkeuze, blijft de rol van het meisje daarbij erg secundair en te verwaarlozen. De partnerkeuze, ongeacht of ze door de vader of door de zoon gebeurt, blijft een vorm van éénrichtingsverkeer, waarbij het betrokken meisje weinig of geen zeggingskracht heeft of krijgt, en er evenmin expliciet naar streeft. (Mogelijk is onze informatie in dit opzicht enigzins scheefgetrokken en kennen wij enkel de mannelijke zienswijze. Het ondervragen van vrouwelijke proefpersonen zou deze klemtoon waarschijnlijk verlegd hebben).

In tegenstelling met wat in het Westen als fundamenteel doorgaat, komen bij de partnerkeuze in Afrika berippen als liefde en romantiek nauwelijks ter sprake, de huwelijksaanvraag blijft grotendeels gebaseerd op traditionele criteria, zoals tribale endogamie en clanieke exogamie, eventueel aangevuld met meer moderne gezichtspunten, zoals ontwikkelingsniveau en religieuze overtuiging. Tenslotte is het minder de persoonlijkheid van het meisje die in de partnerkeuze een rol speelt, dan het personage, of de waarborgen die ze biedt om, naar Afrikaanse normen, een goede echtgenote te worden. De relativiteit van deze persoonlijkheidskenmerken komt scherp naar voren in volgend fragment :

"... Le papa insista, en disant : 'prend cette femme, mon fils. ... Si je te laisse l'argent, tu vas tout gaspiller, en plus, si tu ne veux pas de cette femme, il est súr que tu devras un jour 
en chercher une autre. Saches que toutes les femmes sont les mémes, elles ne sont pas tellement différentes'. Le fils consentit et partit avec sa future épouse."

Gezegd kan dus worden dat de modernisering van het huwelijk en familie, voor wat betreft het stadium van de partnerkeuze althans, vrij formeel blijft en zich toespitst op de vraag of het zwaartepunt van deze keuze zich eerder bij de familie situeert dan bij de (mannelijke) betrokkene. Want alhoewel in een aantal verhalen een zekere afkeer tot uiting komt voor het door de vader voorgestelde dorpsmeisje, blijken in de praktijk de stedelingen hun toekomstige vrouw bij voorkeur te recruteren in het ruraal milieu (BERNARD, 1968, p. 56).

Deze moderne instelling geeft echter wel aanleiding tot een reeks problemen en conflictsituaties, vermits men enerzijds streeft naar een meer persoonlijke inbreng bij de partnerkeuze, maar anderzijds de relaties met de familie niet in gevaar wil brengen. De incompatibiliteit van deze beide waarden leidt niet zelden tot uiterst pijnlijke en psychisch moeilijk te verwerken situaties. De synthese van de ambivalente situatie waarin de moderne Afrikaan zich bevindt, kan nauwelijks levendiger onder woorden gebracht worden dan in volgend fragment :

"... il l'a appelé et lui présente, convaincu d'accomplir son devoir, la jeune fille en question. Le garçon a envie d'éclater de rire en voyant celle qu'on lui présente d'épouser. Mais il se retient, par respect, il ne sait quoi dire. S'il refuse, son père sera frustré, s'il accepte, ce sera contre sa volonté et peutêtre les copains se moqueront de lui ..." (nr. 37, bediende).

NOTEN

(1) Zonder ook maar enigzins volledigheid na te streven, denken we aan volgende publikaties : ABBOTT \& ARCURY, 1977 ; ABLEMAGNON, 1962 ; ADJETEY, 1961 ; ALLMAN, 1978 ; BEKOMBO, 1965, 1969 ; BERNARD, 1968, 1972 ; BINET, 1959 ; BOSSEN, 1975 ; CALDWELL \& CALDWELL, 
1977 ; CALDWELL \& WARE, 1977 ; CAMILLERI, 1967 ; CLIGNET, 1972 ; CLIGNET \& SWEEN, 1969, 1971 ; COLSON. 1971 ; COSTA, 1971 ; DALTON, 1966 ; DE JONGHE, 1972 ; DETHIER, 1961 ; DIOP, 1969 ; EYENGA-MOKANZO, 1973 ; FORTES, 1978 ; FORTHOMME, 1957 ; GOODY, 1970 ; GULLIVER, 1961 ; GUTKIND, 1961, 1962 a,b, 1966 ; HANSEN, 1975 ; HENNIN, 1965 ; HARRELL-BOND, 1976, 1977 ; HOLLEMAN, 1961 ; ILLY, 1975 ; JOACKIM, 1962 ; KABA, 1978 ; LEHMAN, 1962 ; LETNEF, 1964 ; LITTLE, 1980 ; LITTLE \& PRICE, 1964 ; MAISTRIAUX, 1964 ; MERE, 1976 ; MERE \& ANIKPO, 1978 ; MOTSHOLOGANE, 1978 ; NICOLLET, 1959 ; OGIONWO, 1975 ; OKEDIJI, 1976 ; OMARI, 1960 ; OPPONG, 1974 ,a,b, 1983 ; PARKIN, 1966 ; PHILLIPS, 1953 . PICHE, 1976 ; POOL, 1972 ; RALIBERA, 1966 ; SEMBAJWE, 1979 ; SCHAPERA, 1966 ; SYMONDS, 1967 ; SWEEN \& CLIGNET, 1974, 1978 ; THOMPSON, 1978 ; THORE, 1964 ; TINKER, 1976 ; TRAORE, 1979 ; VAN DEN BAN, 1968 ; VINCENT, 1963 ; WEISNER \& ABBOTT, 1977 ; WERE, 1975 ; WHITE, 1962 ; WIPPER, 1972 ; ZIMMERMAN, 1974.

(2) Dat dit probleem niets aan actualiteit neeft ingeboet en ook buiten Afrika van belang is, komt tot uiting in een artikel van RAO \& RAO (1976). Een attitudeonderzoek bij 182 Indische studenten wees uit dat slechts ongeveer $20 \%$ der ondervraagde proefpersonen de traditionele procedure, waarbij de toekomstige echtgenote niet gekend is lof niet ontmoet wordt) vooor het huwelijk, blijven waarderen.

(3) Voor een meer volledige informatie over dit onderzoek, zie DRIES, 1984.

(4) Wij baseren ons hierbij op een publikatie van DE SOETE (1982), waarin een dergelijke procedure verdedigd wordt : "in absence of an accurate and practical way for expressing the amount of evidence a dataset provides for a given hypothesis, reporting pvalues can be justified by the fact that they yield more information than merely stating whether or not a result is significant. These $p$-values should however be interpreted with caution !" (p. 300). 
(5) Deze bruidsprijs is bovendien regelmatig oorzaak van spanningen tussen vader en zoon, of kan bestaande conflicten aanscherpen. Zoals we reeds vermelden wordt deze meermaals door de vader als drukkingsmiddel gebruikt om de zoon te dwingen het voorgestelde meisje te huwen. Wanneer in dit geval de zoon niet toegeeft zijn de complicaties uiteraard moeilijk te overzien, vooral indien reeds een gedeelte van deze bruidsprijs vereffend werd. "... Comme dans son temps on lui avait trouvé une femme qu'il avait épousé sans l'avoir aimée, il a cru qu'il fallait faire la même chose pour son fils. Le garçon dit qu'il n'est pas d'accord avec le mariage coutumier. La jeune fille qu'il voudrait épouser se trouve en ville, cette villageoise il ne la connaît pas. Le père se fâche et dit qu'il a déjà doté pour cette fille. Le garcon s'entête aussi. Je crois que c'est le garçon qui aura raison finalement." (nr. 9. bediendel.

\section{BIBLIOGRAFIE}

ABBOTT, S. \& ARCURY, T., (1977) : "Continuity with tradition : male and female in Gikuyu culture". Youth and Society, 8, blz. 329-358.

ABLEMAGNON, F. N., (1962) : "Research on attitudes towards the Togolese woman". International Social Sciences Journal, 14, blz. 148-156.

ADJETEY, P.A., (1961) : "Some consequences of polygamous marriages", Universités, 4, b/z. 168-171.

ALLEN, M., (1972) : "A cross-cultural study of agression and crime", Journal of Cross-Cultural Psychology. 3. blz. 259-271.

ALLMAN, J., (1978): "Family pattern, women"s status and fertility in the Middle-East and North Africa". International Journal of Sociology of the Family, 8 , blz. 19-35. 
BEKOMBO, M., (1978): "Les relations familiales en Afrique Noire d'hier à demain. Transformations et difficultès actuelles des relations et de l'éducation familiales dans les differents pays."

Conférence Internationale de la Fédération des Ecoles des Parents et d'Educateurs. Ministère de l'Education et de la Culture, Bruxelles, blz. 146-150.

BEKOMBO, M., (1969) : "Autorité parentale et délinquance juvénile en Afrique", Psychopathologie Africaine, 5 , b|z. 101-121.

BERNARD, G., (1968) : Ville Africaine, famille urbaine ; les enseignants de Kinshasa, La Haye, Mouton.

BERNARD, G., (1972) : "Conjugalité et rôle de la femme à Kinshasa", Canadian Journal of African Studies, 6 , b|z. 261-274.

BINET, J., (1959) : Le mariage en Afrique Noire, Paris, Editions du Cerf.

BOSSEN, L., (1975) : "Women in modernizing societies". American Ethnologist, 2, blz. 587-601.

CALDWELL, J.C. \& CALDWELL, P.. (1979): "The role of marital sexual abstinence in determining fertility : a study of the Yoruba in Nigeria". Population Studies, 31. blz. 193-217.

CALDWELL, J.C. \& WARE, H., (1979): "The evolution of family planning in an African city : Ibadan, Nigeria", Population Studies, 31, blz. 487-507.

CAMILLERI, C., (1967): "Modernity and the family in Tunisia", Journal of Marriage and the Family, 29, blz. 590-595.

CLIGNET, R., (1972): "Quelques remarques sur le rôle des femmes Africaines en milieu urbain : le cas du Cameroun", Canadian Journal of African Studies, 6, blz. 303-315.

CLIGNET, R. \& SWEEN, J., (1969): "Social change and type of marriage". American Journal of Sociology, 75. blz. 123-145.

CLIGNET, R. \& SWEEN, J., (1971): "Traditional and modern life styles in Africa", Journal of Comparative Family studies, 2, blz. 188-214.

COLSON, E., (1962) : "Family change in contemporary Africa", Annals of the New York Academy of Sciences, 96, blz. 641-652. 
CosTA, J., (1971): "La nouvelle famille Africaine dans les droits de l'indépendance : essai de sociologie normative". Annèe Sociologique, 22, blz. 153-180.

DALTON, G., (1966) : "Bridewealth' versus 'Brideprice"", American Anthropologist, 68, blz. 732-738.

DE .JONGHE, K., (1972) :"Mythe en realiteit van geboortebeperking in Afrika", Kroniek van Afrika, 12, blz. 120-131.

DEKKERS, R., (1968) :" Dynamique de la dot", In E. LAMY (Ed.) : Colloque sur la dot; situation actuelle et son avenir. Lubumbashi, Mëmoires du CEPSI, No 27.

DE SOETE, G., (1982): "A note on the use of critical levels and $p$-values for iriformative inference",

Psychologische Beitrage, 24, blz. 296-301.

DETHIER, R., $(1961, a$.$) Les citadins Katangais et leur jardiri;$ aspects psycho-sociaux de la vie en milieu Africain urbain, Liège, Imprimerie Vaillant-Carmauve.

DETHIER, R., (1961,b.) "Une famille de citadins du Katanga", Travaux de l"Institut de Sociologie de la Faculté de Oroit de Liège, XI.

DRIES, H., (1984) : De psychologie van de moderrie Afrikaarı: een psycho-antropologische benadering van het modernisatieproces in Zaire, Lisse. Swets \& Zeitlinger. EYENGA-MOKANZO, M., (1973) : "La transformation de la famille traditionelle Zairoise a Lubumbashi", Synthèses, 1, blz. 3-22.

FORTES, M., (1978): "Parenthocd, inarriage and fertility in West.Africa", Journal of Developmental Studies, 14, blz. 121-149.

FORTHOMME, G., (1957) : Mariage et évolution : évolution de la mentalité indigène dans une cité de travailleurs d'Elisabethville, Liège, Vaillant.

GOODE, W.J., (1973) : World revolution and family patterns, New York, The Free Press.

GOODY, J., (1970): "Sideways or downwards? Lateral and vertical succession, inheritance and descent in Africa and Eurasia", Man, 5, blz. 627 -638.

GOUGH, H.G., (1977): "Further validation of a measure of individual modernity", Journal of Personality Assessment, 41, blz. 49-57. 
GULLIVER, P.H., (1961): "Bride-wealth; the economic vs. the noneconomic interpretation", American Anthropologist, 63, blz. 1098-1100.

GUTKIND, P.C.W., (1961) : "Some problems of urban African family life : an example from Kampala, Uganda, British East Africa", Zaire, 15, blz. 59-74.

GUTKIND, P.C.W., $(1962$, a.) : "African urban family life", Cahiers d'Etudes Africaines, 3, blz. 149 217.

GUTKIND, P.C.W., $(1962, b$.$) : "La famille Africaine et son$ adaptation à la vie urbaine. Quelques aspects du problème d'après une étude effectuée a Kampala, Ouganda". Diogène, 37, blz. 93-112.

GUTKIND, P.C.W., (1966): "African urban family life and the urban system", Journal of Asian and African Studies, 1. blz. 35-42.

HANSEN, K.T., (1975) : "Married women at work : explorations from an urban case study". African Social Research, 20. blz. 777-799.

HARRELL-BOND, B.E., (1976) : "Stereotypes of Western and African patterns of marriage and family life". Journal of Marriage and the Family, 38, blz. 387-396. HARRELL-BOND, B.E., (1977): "The influence of the family caseworker on the structure of the family: the Sierra Leone Case", Social Research, 44, blz. 193-215. HENNIN, R., (1965) : "Les structures familiales en milieu urbain", Problèmes Sociaux Congolais, 68, blz. 3-90. HOLLEMAN, J.F., (1961) : "Bantu marriage at the cross-roads", Race Relations Journal, 28, blz. 12-23, 32-44. HUNTER, G., (1967): "From the old culture to the new", In J.M. MCEWAN \& R.B. SUTCLIFFE (eds.) : Modern Africa, New York. Thomas Y. Crowell Company, blz. 315-325. ILLY, L.B., (1975) : "Afrikanische Familienstrukturen zwischen "Tradition" und "Modernität" : Fallstudie Kamerun", Die Dritte Welt, 4, blz. 368-390.

JAHODA, G., (1959) : "Love, marriage, and social change : letters to the advice column of a West African newspaper". Africa, 29, blz. 177-190. 
JOACKIM, P., (1962) : "Vers la suppression de la dot et de la famille polygamique en Afrique", Communeauté France-Eurafrique, 14, b|z. 14-17.

KABA, B.D., (1978) : "Relationships between women's economic activities and their family behaviour and expectations in Liberia", Institute of African Studies, b|z. 2667.

LEHMANN, D., (1962) : "African urban marriage in Northern Rhodesia", African Women, 5, blz. 15-16.

LETNEV, A.B., (1964): "Problems in the development of family relations in West Africa". International Social Sciences Journal, 16, b.12. 400-410.

LITTLE, K., (1980): The sociology of urban women's image in African literature, London. The MacMillan Press.

LITTLE, K. \& PRICE, A., (1967): "Some trends in modern marriage among West Africans", Africa, 37, blz. 407-424. LLOYD, 8.8., (1966): "Education and family life in the development of class identification among the Yoruba". In P.C. LLOYD (ed.) : New elites of Tropical Africa, London, Oxford University Press, blz. 163-183.

LOMBARD, J., (1954) : "Cotonou : ville Africaine", Bulletin de l'Institut Français d'Afrique Noire. 16. blz. 3-4.

MAISTRIAUX, R., (1964): La femme et le destin de l'Afrique, Elisabethville, Editions CEPSI, Collection de Mémoires, vol. 16.

MARRIS, P., (1961): Family and social change in an African city, London, Routledge and Kegan Paul.

MERE, A.A., (1976) : "Contemporary changes in Igbo family system", International Journal of Sociology of the Family, 6, blz. 155-160.

MERE, A.A. \& ANIKPO, M., (1978): "The Igbo family system in change", Institute of African Studies, Accra, University of Ghana.

MONONI, F., (1968) : "Faut-il réglementer la dot Congolaise ?", In E. LAMY (ed.) : Colloque sur la dot ; situation actuelle et son avenir, Lubumbashi, Mémoires du CEPSI, 27, blz. 243-262. 
MOTSHOLOGANE, S.R., (1978): "Influence of urbanization on the role and status of husband and wife in the Tswana family", Suid-Afrikaanse Tydskrif vir Sosiologie, 17. blz. 83-90.

MWEPU-KYABUTHA, G., (1967): "Quelques aspects des conséquences sociales de l'industrialisation au Katanga", Civilisations, 17, blz. 53-69.

NICOLLET, A., (1959) : "La femme, la famille et les changements économiques en Afrique Noire". Cahiers de Sociologie Economique, 1, blz. 19-38. OGIONWO, W., (1975) : "Family structure and development : cart and horse or chicken and egg ?", International Journal of Sociology of the Family, 5, blz. 53-65. OKEDIJI, F.O., CALDWELL, J., CALDWELL, P. \& WARE, H., (1976): "The changing African family project: a report with special reference to the Nigerian segment", Studies in Family Planning, 7, blz. 126-136.

OMARI, T.P., (1960): "Changing attitudes of students in West African society towards marriage and family relationships", British Journal of Sociology, 11. blz. 197-210.

OMARI, T.P., (1962) : Marriage guidance for young Ghanaians, Edinburgh, University of Edinburgh Press.

OPPONG, C., $(1974$, a.) : "Attitudes to family size among unmarried junior civil servants in Accra", Journal of Asian and African Studies, 9, b/z. 76-82.

OPPONG, C.. (1974,b.): "Attitudes toward family type and family size in West Africa : a study of norms among a Ghanaian student population", International Journal of the Family, 4, blz. 170-178.

OPPONG, C., (ed.), (1983): Female and male in West Africa, Hemel Hempstead, George Allen \& Unwin.

PARKIN, D.J., (1966): "Types of urban African marriage in Kampala", Africa, 36, blz. 269-285.

PHILLIPS, A., (1953) : Survey of African marriage and family life, Oxford, University Press.

PICHE, V., (1976): "Les enquêtes de fécondité en Afrique Tropicale ou le principe du double standard". Population et Famille, 37, blz. 143-164. 
POOL, J.E., (1972): "A cross-comparative study of aspects of conjugal behavior among women of three West-African countries", Canadian Journal of African Studies, 6 , blz. 233-259.

RALIBERA, R., (1966) : "La famille Malgache évolue, elle aussi", Afrique Documents, 88-89, blz. 299-302.

RAYNER, W., (1962): The tribe and its successors, London, Oxford University Press.

SCHAPERA, I., (1966): Married life in an African tribe, EVANSTON, III., Northwestern University Press.

SEMBAJWE, I., (1979) : "Effect of age at first marriage, number of wives, and type of marital union on fertility". Journal of Biosocial Sciences, 11, blz. 341-351.

SWEEN, J.A. \& CLIGNET, R., (1974): "Type of marriage and residential choices in an African city", Journal of Marriage and the Family, 36, blz. 780-793.

SWEEN, J,A, \& CLIGNET, R,. (1978): "Historical changes in the influence of the status of women on fertility, in West Cameroun", African Studies, 15, blz. 23-45.

SYMONS, H.J., (1967): "The status of African women", in J.M. MCEWAN \& R.B. SUTCLIFFE (eds.): Modern Africa, New York, Thomas Y. Crowell Company, blz. 326-331.

TARDITS, C., (1958) : Porto Novo, Paris, P.U.F.

THOMPSON, R.W., (1978) : "Fertility aspirations and Modernization in urban Uganda : a case of resilient cultural values", Urban Anthropology, 7, blz. 155-170.

THORE, L., (1964) : "Polygamie en Afrique Noire", Revue de l'Action Populaire, 15, blz. 807-827.

TINKER, I., (1976): "Development and the disintegration of the family", Carnets de l'Enfance, 36, b/z. 29-37.

TRAORE, A., (1979): "Evolving relations between mothers and children in rural Africa", International Social Science Journal, 31, blz. 486-491.

VAN DEN BAN, A.W., (1967) : "Family structure and modernization", Journal of Marriage and the Family, 29, blz. 771-773.

VAN DEN BERGHE, P., (1970): "Major themes in social change", In J.N. PADEN \& E.W. SOJA (eds.) : The African experience, Vol. 1.. : essays, Evanston, Northwestern University Press, blz. 252-275. 
VINCENT, J.F., (1963) : "L'évolution féminine dans les villes", Afrique Documents, 70-71, blz. 191-193.

WEISNER, T.S. \& ABBOTT, S., (1977) : "Women, modernity, and stress : three contrasting contexts for change in East-Africa", Journal of Anthropological Research, 33. blz. 421-451.

WERE, H., (1975): "The limits of acceptable family size in Western Nigeria", Journal of Biosocial Science, 7. blz. 273-296.

WHITE, C.M.N., (1962): Tradition and change in Luvale marriage, Manchester, Manchester University Press.

WIPPER, A., (1972) : "African women, fashion, and scapegoating", Canadian Journal of African Studies, 6 , blz. 329-349.

ZIMMERMAN, C.C., (1974): "Family systems of the third world". International Journal of Sociology of the Family, 4, b|z. 1-10. 